\title{
KOMIMUNIKASIE As metode om verpleegsorg te verbeter
}

\section{G. POSTMUS}

Senior Matrone

\section{Geregistreerde Algemene, Psigiatriese, Gemeenskaps- en Ortopediese Verpleegkundige en Vroedvrou, Diploma in Verpleegadministrasie (UP)}

\section{SUMMARY}

With the large number of patients in particularly academic hospital wards and the shortage of nursing staff total patient care is not possible. This is leading to increasing task-orientation and a widening of communication gaps which are affecting the quality of nursing care.

One of the main problems is that it is impossible for nurses to remember all the details given during the regular reports off by heart. Neither does the nurse know which regular oral medications each patient is receiving. The nurse is thus unable to make the required observations while doing patient care and does not provide the necessary feedback.

The author suggests a simple system, based mainly on the use of patient bed lists and a note book carried by each nurse to improve communication and achieve a higher standard of nursing care within a short period.

\section{INLEIDING}

Weens die groot aantal pasiënte in veral akademiese hospitaalsale (2536 pasiënte per saal) en die min verpleegpersoneel, kan totale pasiëntsorgverpleging oor die algemeen nie uitgevoer word nie. Dit bring mee dat die verpleegkundiges te prosedure, dus taakgerig, raak, en dat die kommunikasieprobleme al wyer word, waardeur die kwaliteit van verpleegsorg agteruitgaan.

\section{Drie kriteria vir goeie gehalte van verpleegsorg}

Die bespreking is gebaseer op die drie kriteria vir goeie gehalte van verpleegsorg van Hausman, naamlik:

Written report on all information, by all concerned with the treatment, the nursing and caring for the patient.
The information must be provided of: date, time, signature, with qualifications.

The reaction of the patient, on being ill, and on the treatment, on the nursing care, must repeatedly, continuously be reported! (Hausman, 1975, p. 3)

\section{Die implementering van die kriteria}

Deur wie behoort die kriteria geïmplementeer te word en hoe?

Die bogenoemde definisie vereis 'n geskrewe verslag met alle inligting, deur almal betrokke by die behandeling en verpleegsorg van die pasiënt.

Almal impliseer dus dat die saalsuster, dit is die geregistreerde verpleegkundige, sowel as die studentverpleegkundige, leerlingverpleegkundige, verpleegassistent, asook die paramediese personeel betrokke (fisioterapeut, arbeidsterapeut, onderwyseres, maatskaplike werker en so meer), akkurate in skrywings van hulle waarnemings, behandeling en verpleegsorg in die pasiëntvorderingsverslag moet maak.

Die inligting moet voorsien wees van datum, tyd, handtekening en kwalifikasies van die betrokke persone.

Die reaksie van die pasiënt, óp sy siekwees, óp die behandeling, óp die verpleegsorg, moet gereeld en aanhoudend gerapporteer word

Dus word die fisiese sowel as psigiese reaksies van die pasiënt skriftelik deur alle betrokke lede van die gesondheidspan in die pasiënt se vorderingsverslag in die dienskamer gerapporteer.

\section{TOEPASSING VAN DIE KRITERIA}

Ondervinding in die praktyk het aan die lig gebring, dat daar huidig weinig teregkom van die toepassing van die bogenoemde drie kriteria vir goeie kwaliteit van pasiëntsorg in die meeste van ons akademiese hospitale.

Wat is die redes hiervoor?

\section{Taakgerigtheid}

Geen totale pasiëntsorg kan uitgevoer word nie, weens die redes genoem in die inleiding. Die verpleegkundige word te veel taak- en prosedure gerig. Sy is op Opnames, of op rug-en drukplekversorging of op Temps! Sy leer nie om die pasiënt in sy geheel, as 'n psigiese, fisiese en sosiale wese te sien nie.

Daar ontstaan selde ' $n$ goeie verpleegkundige/pasiënt verhouding, en haar belangstelling in die verpleging van pasiënte neem naderhand af. 


\section{Verslaggewing}

Die verpleegkundige kan onmoontlik nie ál die pasiënte in die saal, met hul name, diagnoses, medikasies en behandelings, onthou nie. Dus kan sy óók nie (na sy die vroeë oggend verslag oor al die pasiënte in die saal gehoor het) presies onthou by watter pasiënt sy wat moet waarneem en skriftelike terugvoering oor moet gee nie.

Geen verpleegster behoort aan diens te gaan voordat sy nie eers verslag oorgeneem het nie sodat sy onder andere kan waarnemings doen van pasiënte, met betrekking tot verwagte simptome en reaksies op behandeling (Searle, C, p. 61).

Die verslag word ook in baie sale nie meer stiptelik vyf maal per dag gegee nie. Dus word waardevolle inligting nie aan die verpleegkundiges verstrek of terugvoer van hulle verkry nie. (Die saalsuster kan onmoontlik nie self by elke pasiënt hoor, sien, voel, ruik vir dit wat afwyk van die normale nie. Hierdie opdragte delegeer sy aan die verpleegkundiges, wat dan die inligting behoort terug te voer.)

\section{Kennis van Medikasies}

Roetine medikasievoorskrifte vir pasiënte (soos orale antibiotika, bloeddruk behandelings, medikasies vir hart-, long-, lugweg- en niersiektes), word met aanvang van die behandeling slegs eenmaal in die vorderingsverslag aangeteken, dan direk op inspuitings- en medisynelyste oorgeskryf.

Medikasies word periodiek, volgens die lyste en voorskrifkaarte, deur die betrokke senior verpleegkundige uitgegee. Dit impliseer dat die verpleegkundige selde hoor watter pasiënt vir watter siekte met watter middels behandel word. Sy leer dus nie werklik om die diagnose van die pasiënt met sy/haar behandeling te assosieer nie. Nog belangriker, sy leer ook nie om die reaksie van die pasiënt op sy/haar medikasie of newe-effekte van medikasies waar te neem en terugvoer daaroor te gee nie.

Inskrywings van slegs sekere middels word na toediening, in die pasiëntvorderingsverslag gemaak (byvoorbeeld van binnespierse en binne-aarse toediening van antibiotika, insuline inspuitings, bloedverdunnings-middels en gewoontevormende middels). Inskrywings van die roetine orale medikasies word dus nie gemaak nie.

Die senior verpleegkundige in die saal, kry slegs 'n paar maal per week die geleentheid om medikasie voorskrifte volgens die medisynelyste uit te gee. Sy sien dàn eers op watter medikasies die pasiënt nou eintlik is.

Hoe leer elke verpleegkundige in die saal nou om tydens pasiëntsorg, die waarnemings van die pasiënt se reaksie op medikasie en behandeling te maak, as sy (soms ook) nie eers weet wie die pasiënt is nie, en nog minder weet wat sy/haar behandeling is.

Gevallestudies, deur verpleegkundiges gedoen, is noodsaaklik en baie waardevol. In die praktyk kan dit egter eintlik net in die vrye tyd gedoen word.

\section{Doktersrondte}

Die geneesheer op sy daaglikse rondte verlaat hom op die saalsuster en haar verpleegpersoneel, vir die uitwys van sy pasiënte en hulle vordering.

Die saalsuster moet die pasiënt korrek kan identifiseer, en die geneesheer volledig inlig oor die pasiënt se toestand in die tydperk sedert sy voorafgaande besoek. (Searle, C. p. 61)

Sy moet ook 'n oog kan hou oor bestaande opdragte, ingeval die geneesheer vergeet om dit te wysig. Dit is byvoorbeeld haar plig om dit onder die geneesheer se aandag te bring wanneer die toediening van medisyne die gebruiklike tydperk bereik het.

As sy nie vir haarself nota's gemaak het nie, maar op haar geheue staatmaak, kom daar nie genoeg tersaaklike en korrekte inligting deur na die geneesheer nie.

Ander geneeshere wat terselfdertyd rondtes kom doen en sien dat die saalsuster besig is, gaan nou maar alleen hulle pasiënte besoek. Hulle sal nooit 'n ander verpleegkundige vra om hulle te vergesel nie want hulle dink dat sy in elk geval niks van die pasiënte af weet nie. (Hoe kan hulle ook alles uit hul kop onthou!)
As elke verpleegkundige oorsigtelik alle tersaaklike daaglikse inligting van die pasiënte in haar sakboekie sou inskryf, kon enige een van hulle immers 'n geneesheer vergesel.

Die saalsuster op haar rondte met Dr. A sien nou vir Dr. B inkom wat 'n frustrasie vir haar! Sy moet vir Dr. B iets vra oor 'n pasiënt of miskien probleme van 'n pasiënt oordra. Sy kan nou ongelukkig nie vir Dr. A alleen op sy rondte laat verder gaan nie. Die gevolg? Sy moet Dr. B nou maar later telefonies kontak!

Intussen stap Dr B nou alleen na sy pasiënte. Hy kom nie te hore van mev. X se hoë temperatuur nie en doen dus niks daaraan nie; hy belowe vir mev. $Y$ 'n slaappil, maar vergeet om dit voor te skryf. As sy vanaand vir die nagsuster daarvoor vra, mag die nagsuster dit nie uitgee nie, want dit is die voorgeskryf nie. Onmiddellik het die pasiënt haar vertroue in haar geneesheer en in die verpleegpersoneel verloor!

Die grootste probleem in ons tyd met verpleging in hospitale is nie die menslike faktor nie - ons het pragtige materiaal - maar wel die probleem van wye kommunikasiegapings, wat onherroeplik gaan lei tot 'n al meer verswakkende kwaliteit van pasiëntsorg. Weens al hierdie kommunikasieprobleme in akademiese (en ander) hospitale loop daar baie meer dinge verkeerd as wat werklik besef word. En dit is tog só onnodig!

\section{WYSIGINGS OM DIE DRIE KRITERIA MEER SUKSESVOL TOE TE PAS}

Ter wille van beter navolging van die drie kriteria is daar vir een week in agtien sale van ' $n$ akademiese hospitaal ' $n$ nuwe benadering gevolg. Die sale was hoofsaaklik met eerstejaars en beginnende tweedejaar studentverpleegkundiges beman.

Om kommunikasieprobleme te voorkom en praktiese vraagstukke op te los, is alle studentverpleegkundiges in twee groepe vir omtrent 'n halfuur georiënteer. 


\begin{tabular}{|l|l|l|l|l|l|l|}
\hline & Pasiënt & Dokter & Opnamedatum & Operasiedatum & Diagnose & Globale behandeling \\
\hline & & & & & & \\
\hline 1 & 1 & & 1 & 1 & 1 & 1 \\
\hline 1 & 1 & 1 & 1 & 1 & 1 & 1 \\
\hline
\end{tabular}

Die studente se pligte en verantwoordelikhede vir pasiëntsorg waarneming, waar hul vier sintuie gedurig aktief werk, rekordhouding daarvan, verpleegadministrasie, opleiding van junior personeel en bediendes, diensvoorwaardes, etenstye is onder andere saam met die beginsels van die nuwe benadering bespreek.

\section{Die benadering}

Die beginsels van die nuwe benadering wat gevolg was word vervolgens uiteengesit. Pasiëntbedlyste, met 'n uitleg van elke saalbedposisie, pasiënt, diagnose en so meer (sien figuur 1) is uitgereik aan elke saal. Lyste is deur die senior studentverpleegkundige in potlood voltooi. Dit is elke aand gedurende besoektyd op datum gebring (vir gebruik vir hulp-aflospersoneel, nagsusters en nag- en dagmatrones).

Pasiëntvorderingsverslae is op ontruimde oorbedtafels by die voetenend van elke bed geplaas. Hier kon hulle vinnig deurgelees word, voordat die verpleegkundige die pasiënt versorg.

Buiten die intraveneuse en intramuskulêre inspuitings, bloedverdunningsmiddels, en gewoontevormende middels was daar ook van die roetine 4-uurlikse medikasies, uitgegee deur die nagstaf, inskrywings in die vorderingsverslae gemaak. Sodoende het elke verpleegkundige, tydens die $07 \mathrm{~h} 00$ verslag aan die dagstaf tenminste een maal per dag gehoor watter pasiënt met watter middels vir welke siektetoestand behandel word.

Die drie-maal-per-dag medikasies kon nie gemeld word nie, omdat dit nie deur nagstaf uitgegee was nie.

Omstreeks middernag, dus eenmaal per nag, is daar deur die senior verpleegkundige 'n kruiskontrolering gedoen van alle doktersvoorskrifkaarte met inskrywings op medisyne-, inspuitings- en verbandlyste en foute is reggestel.
Om mediese geregtelike risiko's uit te skakel, is geen enkele ondersteek of urinaal snags by die pasiënte se beddens gelaat nie, en pasiënte is vooraf daaromtrent ingelig en gerusgestel.

'n Gedempte liggie aan die begin en einde van die groot saal het beter toesig verseker.

Pasiëntrondtes is een-tot-twee uurliks gedoen met, behalwe die waarneming van die bewussynstoestand van die pasiënt, ook kontrolering van infuse, oop- en geslote dreineringstelsels en so meer. Alle waarnemings is onmiddelik op die kardeksverslag by die voetenend van die bed noteer.

Die eenmalige nagverslag, gewoonlik om 03 h00 deur die senior studentverpleegkundige geskryf is vervang deur rekordhouding tydens rondtes waar inskrywings in die vorderingsverslag gemaak is deur elkeen wat self die pasiënt versorg het. Die nagsusters, elkeen verantwoordelik vir tenminste drie sale, het op minstens een van hul volle rondtes in elke saal die pasiëntvorderingsverslag by elke pasiënt geteken.

Iets van saaladministrasie is geleer, byvoorbeeld studente het self werksbestellings vir defektiewe ligte en skakelaars geskryf. So ook is iets van hospitaalbeleid geleer deur enkele interne omsendbriewe te lees en te verstaan.

\section{BEVINDINGS NA EEN WEEK}

Die bevindings na ' $n$ week van die nuwe benadering was dat:

- daar oor die algemeen 'n rustiger atmosfeer geheers het in die sale, al was dit dikwels ook hoé besig, met baie siek pasiënte, opnames, operasies en so meer

- daar deur verbeterde toesig en die voorkoming van rusteloosheid, geen ongelukke (val uit bed uit) gebeur het nie. Ook het geen enkele infuus gedurende die hele week in die weefsels geloop nie
- die verpleegkundiges, die verantwoordelikheid van hul werk besef het, hulle betrokke gevoel het, en voldoening gevind het in hul bydrae en trots daarop was. Hulle het die belangrikheid van vermeerderde pasiëntrondtes met skriftelike rekordhouding ingesien

- veral die juniorgroep reeds duidelike blyke getoon het van die goeie basiese kliniese opleiding wat met soveel moeite en toewyding gegee word

- die groep wat dangemoedig was beter presteer het

- dit opvallend was hoe ontvanklik vir leer en dankbaar vir ondersteuning, leiding, dissipline en erkenning, die junior studentverpleegkundiges is.

Die slotsom na die week nagdiens was dat daar 'n taakvolvoering verkry was, deur mense wat betrokke gevoel het, weens 'n gemeenskaplike aandeel in die doel van die organisasie. Dit het gelei tot verhoudings van wedersydse vertroue en respek (Hausman, C. p. 3).

Geneeshere wat op 'n laat rondte onmiddellik verwittig kon word van hulle pasiënte se omstandighede was uiters dankbaar. Elke studentverpleegkundige, hoe junior ook al, kon op 'n intelligente wyse met die geneesheer 'n rondte doen!

\section{AANBEVELINGS}

Dit het noodsaaklik geword dat daar 'n vaste stelsel van geskrewe kommunikasie gebruik word. Die instelling en gebruik van 'n pasiëntbedlys en sakboekies, soos hieronder beskryf, word aanbeveel.

\section{Pasiëntbedlys}

Die pasiëntbedlys moet die gegewens van elke pasiënt in die afdeling, soos aangedui in figuur 1 , bevat. 
Die lys behoort as hulpmiddel gebruik te word deur aflospersoneel en sonematrones op hul pasiëntrondtes (sodat hulle ook meer effektief raad, ondersteuning en situasionele onderrig kan gee aan pasiënte, susters en ander verpleegpersoneel). Dit máák die pasiënt se dag, as die senior matrone hom op sy van aanspreek en ook laat blyk dat sy alles van die pasiënt af weet en in hom belangstel.

Hierdie bedlyste behoort op datum gehou te word. Bedags deur die verpleegkundige, gemoeid met opnames, oorplasings en so meer en snags deur die senior verpleegkundige. Slegs die opskrifte en lyne word met 'n pen geskryf en alle verdere inskrywings met potlood. Dit is nie ' $n$ taak wat die saalklerk behoort te doen nie, dit is 'n suiwer verpleegadministratiewe opdrag en leerhulpmiddel vir die studente.

\section{Sakboekies}

Sakboekies word as hulpmiddel vir alle verpleegpersoneel in groot sale gebruik. Hulle word dieselfde uitgemaak as die bedlys, maar nou oor 'n dubbele bladsy, met 3-4 reëls vir elke pasiënt. Behalwe vir die globale behandeling word al die daaglikse tersaaklike pasiëntsorginligting tydens die verslag ingeskryf. Waarnemings by die pasiënt tydens verpleegsorg word voorlopig daarin geskryf om daarna 'n inskrywing in die vorderingsverslag te maak.
Daar is gevind dat in sale waar die saalsuster self alles so noteer in haar boekie, en dit ook van haar personeel verwag, dit opmerklik beter gaan met pasiëntsorg as in ander sale waar geen skriftelike kommunikasiemiddels gebruik word nie.

\section{SAMEVATTING}

Dit is lank genoeg ondervind en bewys dat geen verpleegkundige wat in 'n groot saal werk, op haar geheue kan staatmaak nie, al probeer sy haarself wysmaak dat sy dit wel kan doen. Die kleinste stukkie potlood werk beter as die beste geheue.

Bogenoemde bedlyste en sakboekies behoort 'n vaste hospitaalbeleidsvoorskrif, 'n reël, te wees in alle hospitale waar totale pasiëntsorgverpleging (soos wel in intensiewe sale gegee word) nie moontlik is nie. Daar behoort streng by die reël gehou te word.

Geen verpleegkundige behoort toegelaat te word om 'n pasiënt te gaan verpleeg sonder dat sy nie eers in haar boekie seker gemaak het wie die pasiënt is, wat sy of haar diagnose is, en wat sy moet waarneem nie.

As elkeen by hierdie skriftelike kommunikasie hou, kan 'n baie beter kwaliteit van pasiëntsorg binne 'n kort tydperk verkry word. Dit sal ook meer werksbevrediging by die verpleegpersoneel in die hand werk. Hulle voel dan baie meer betrokke, veilig, en ook dat hulle ' $n$ bydrae lewer en ook daarvoor openlik erkenning kry deur die saalsuster wanneer die volgende verslag gelees word.

Die saalsuster sal baie meer verseker voel en haar pligte ook beter aan haar personeel kan delegeer. (Soos onder andere rondtes met geneeshere, as sy self met ander funksies of rondtes besig is.)

Die junior suster sal nie meer daarvoor hoef weg te skram om met die geneesheer ' $n$ rondte te doen nie. Sy voel nou meer veilig met al die nodige inligting oor elke pasiënt, opgeskryf in haar sakboekie, by haar.

Die saalsuster sal meer werksbevrediging kry, omdat sy haar saal weer kan beheer en ook 'n ware rolmodel vir haar verpleegkundiges kan wees.

Met bogenoemde kommunikasiemiddele en goeie toesig kan 'n baie beter kwaliteit van verpleegsorg amper oornag gelewer word. Daarmee saam, sal die status van ons pragtige professie beduidend verhoog word. Ten spyte van ernstige personeeltekorte is die personeel van 'n hoë gehalte beskikbaar ons moet dus ook 'n hoë gehalte van diens lewer.

\section{BRONNELYS}

1. Felinek, R.C.; Hausman. G. A methodology for monitoring quality of nursing care.

2. Searle, C. Verpleegadministrasie I, gids 2, Pretoria UNISA

3. Blake. A.; Mouton, F. Leierskapsryl.

\section{MODERN CLINICAL NURSING AND APPLIED SCIENCES PART I}

\author{
by G M Rykheer
}

\section{Published by the author, available from the SA Nursing Assocation publication section.}

This book is an outstanding achievement by the author to integrate theoretical and clinical aspects of Nursing under "one umbrella".

The text is systematically set out and the many drawings throughout nearly every chapter introduce difficult concepts so that they are easily understood.
Additional chapters have been added to this new edition for example the author's theory about the nursing process, ward education, administration and economy and an introduction to medical etymology. The specialised subjects are superbly written.

If the student knows this book she will be equipped with sufficient nursing knowledge to will enable her to be an efficient nursing practitioner. I foresee that it will be prescribed in schools of nursing nationally and internationally, therefore it will be of great value and benefit to nurses for years to come.

Apart from being a valuable textbook for student nurses, it will also be useful as a reference work for practising health professionals.

\section{S Oosthuizen}

Vice-Principal, B G Alexander Nursing College. 